\title{
Library and Information Science Journal Editors' Views on Query Letters
}

\section{Meris Mandernach Longmeier and Jody Condit Fagan}

\begin{abstract}
Query letters may offer an effective way to increase author engagement in the scholarly communication process, yet they are not a common practice in library and information science (LIS). A survey and interviews were conducted with LIS journal editors to explore experiences, attitudes, and opinions concerning query letters. Results indicate query letters can be of great benefit to both authors and editors, if approached properly. Yet editors expressed varying levels of enthusiasm and offered some divergent opinions. Such editorial inconsistencies may contribute to authors' uncertainty and anxiety. Thus, this article concludes with ideas for empowering authors and improving editor-author communication.
\end{abstract}

\section{Introduction}

Recent decades have seen librarians' value for openness and transparency in scholarly communication manifest in ways beyond open source and open access. Journals and other scholarly publications in library and information science (LIS) are exploring a variety of ways to empower and encourage authors to become more engaged in the publication process. By fostering connections earlier in the process, editors' experience can help inform authors' ideas and methodologies while it is still easy to correct course. More informal communication, well in advance of peer review, may also reduce author anxiety.

Authors and editors have highly convergent interests in finding a good fit between an author's work and the journal's mission. However, authors typically begin at a disadvantage, with far less information about and power within the article's review and publication process. Since most librarians don't learn about research or publishing in library school, ${ }^{1}$ newcomers to the profession are especially likely to find journal article submission processes to be a mysterious journey, full of unwritten rules and hidden norms and expectations. Meanwhile, journal editors are challenged to provide guidance to authors about best practices and how authors can engage more actively in the publication process. One approach to overcoming these gaps in author-editor communication, which the authors of this study have employed, is to write query letters to potential publication venues. Yet when we have mentioned this practice to colleagues, the idea is often unfamiliar. And we realized our personal experiences may not represent the gestalt.

\footnotetext{
* Meris Mandernach Longmeier is Associate Professor, Head of Research Services, at The Ohio State University; email: longmeier.10@osu.edu. Jody Condit Fagan is Professor, Strategic Research and Assessment Librarian, at James Madison University; email: faganjc@jmu.edu. @2021 Meris Mandernach Longmeier and Jody Condit Fagan, Attribution-NonCommercial (https://creativecommons.org/licenses/by-nc/4.0/) CC BY-NC.
} 
With this in mind, we set out to research editors' views about and experiences with query letters. For the purposes of this article, the survey, and interviews administered therein, the authors defined a query letter as an informal email to the journal concerning the suitability of the authors' manuscript for publication by that journal. Typically, a query letter is submitted outside of the formal reviewing process employed by the journal for article submissions. Some sample query letters created by the authors based on our own experiences and aligned with survey responses can be found here: http://hdl.handle.net/1811/92283.

\section{Literature Review}

Query letters are commonplace for proposing topics for books or journal special editions, but less common for typical journal articles. In searching the literature, query letters are most common in the nursing and education fields. ${ }^{2}$ A 2010 survey of 63 journal editors published in Nurse Educator revealed that 54 percent of respondents found query letters to be somewhat important or very important. ${ }^{3}$ These authors also provided specific recommendations about query letters from the American Journal of Nursing. In a guest editorial for the Journal of the American Association of Nurse Practitioners about query letters, Michael Marinello pointed out that query letters are important, save authors significant work, and build professional rapport. ${ }^{4}$ He detailed the key components of a query letter including the introduction of the author, the topic and its importance in the field, and how the article aligns with the particular journal, as well as areas to avoid in query letters. He also notes the importance of reviewing the journal's information for authors. Patricia Morton created an open educational resource about the process involved in writing journal articles in nursing and included a module partially focused on query letters. ${ }^{5}$ Morton highlighted the importance of finding the right journal for an article and building rapport with the editor.

Similarly, education journals recommend authors submit query letters. In Henson's 1988 study of education journal editors, he addressed common questions authors have, one of which was expected turnaround time for query letter responses. ${ }^{6}$ The 2008 conference report of a profile of education journals by Fairbairn et al. highlighted the usefulness of communication with editors to find a journal that matched the article content. ${ }^{7}$ In early childhood education, an article from $2001^{8}$ and a follow-up study in $2012^{9}$ discussed the process of publication and provided advice for potential authors, both of which highlighted the importance of selecting an appropriate journal.

In library and information science (LIS), journal query letters are mentioned only occasionally. ${ }^{10}$ Michael Lorenzen's 2009 article specifically mentioned query letters for librarians looking to get published. ${ }^{11}$ He noted that the query letter is one method for engaging a journal editor in dialogue about a research topic or proposed article. However, often in professional writing tips for library science, query letters are specifically addressed in the process of writing book proposals rather than queries to journal editors about article topics.

In the LIS literature there have been a couple of studies of journal editors, ${ }^{12}$ as well as numerous articles, ${ }^{13}$ editor panels at conferences, ${ }^{14}$ and even a visual created by Emma Coonan ${ }^{15}$ detailing the steps for publication specifically relevant to library and information science. Yet query letters are often omitted. A 2005 study by Schloegl and Petschnig focused on several aspects of editor views about the publication process for international and German-language LIS journals, ${ }^{16}$ but it did not specifically address query letters as part of the survey. Helen Fallon maintains the Academic Writing Librarians blog (http://academicwritinglibrarian.blogspot. $\mathrm{com} /$ ), which contains a section of "Top Tips" from journal editors in library and information 
science. ${ }^{17}$ This is one of the few places where query letters are explicitly recommended. Several LIS editors indicate that contacting the editor is a valuable part of the research process, once the journal website has been consulted. Based on the thin showing, the authors sought to fill this gap by asking LIS editors about their perceptions of the value of query letters. While the full results are reported in the present article, the authors also wrote a "tips" article based on responses to help authors put theory into practice. ${ }^{18}$

\section{Methodology}

For this study, the researchers surveyed current LIS journal editors to determine best practices and recommendations for LIS authors regarding query letters. The authors created the survey based on their experiences and shared drafts with three editors or former editors of different LIS journals. This study qualified for and was approved as Institutional Review Board-exempt research by James Madison University (IRB \#20-1922). The survey tool employed is found in appendix A.

Our research questions included the following:

- What is the attitude of editors toward receiving query letters?

- How frequently do editors receive query letters?

- Do editors perceive that query letters have an influence on initiating peer review or eventual publication?

- What questions should authors ask in query letters?

- What are editors' perceptions related to the role of the journal website in author communication?

- When in the writing process do editors prefer query letters be submitted?

The authors used Ulrichsweb.com to identify LIS journals. Results were limited to those that were library science (subject_exact: [001661]), actively publishing, classified as academic/ scholarly, and English-language, resulting in 688 titles. That list was pared further by eliminating titles that were not available online, did not contain an ISSN, and did not have any abstracting or indexing of the journal listed, which left 213 titles. Researchers attempted to locate contact information from the journal website or editors' individual website and as part of that process, and they weeded an additional 36 titles due to ceased publication, scope of the journal being outside of LIS, or because the language of publication was no longer English. This left a sample size of 176 titles having 168 editors (three individuals edited multiple journals), and three titles had no named editor. The terms "respondents" and "editors" are used interchangeably in this manuscript to mean an editor's role with a journal.

IBM SPSS version 26 was used for quantitative analysis. As we were interested to explore whether the volume of query letters or editors' attitudes toward query letters influenced their answers to many of the other questions, Fisher's exact test ${ }^{19}$ was used to determine if there was evidence to show relationships between most questions and the number of query letters received (Q3), whether editors appreciated receiving query letters (Q10), and whether editors wished they received more query letters (Q11). If there was evidence, residuals were examined to determine which differences were statistically significant $(p<.05) .{ }^{20}$

Survey participants could elect to be added to an invitation pool for follow-up phone interviews. Interview questions are found in appendix B. Seventeen editors volunteered to be contacted for interviews. Interview candidates were selected to represent journals with broader scope statements and to include some subscription as well as some open access journals. Overall, six editors were contacted for interviews. Due to scheduling constraints, four 
editors were interviewed and represented seven journals with article submission rates of 20, $65,80,95,120,180$, and 400 annually.

\section{Findings}

In total there were 53 responses to the survey, a 30 percent response rate. Results are shared in the same order as the survey. Percentages may not add up to 100 percent due to rounding. The survey started by asking which journal the respondent edits, and 39 respondents provided that information (see appendix C). A few respondents in our sample edited multiple journals and had the opportunity to fill out a survey for each. The names of the journals were used to identify open access journals. Of the respondents who identified their journal, 18 (46\%) of the journals were fully open access and 21 (54\%) were not.

Four of the 53 respondents said they receive no query letters; these respondents did not see more questions on the survey until questions 10-16 (see appendix A). Of these four respondents, two indicated they would "appreciate more query letters." One indicated that their submission process is completely based on query letters as defined by this research and the entire editorial board votes on the proposal.

\begin{tabular}{|c|c|c|}
\hline FIGURE 1 & \\
\hline How many query letters does your journal receive in an average year? $(\mathbf{Q 3}, \boldsymbol{n}=\mathbf{5 3})$.
\end{tabular}

While 11 percent of all editors said they receive "more than 20" query letters per year, the most frequent response was 1-5 (34\%), followed by 6-10 (23\%), 11-15 (15\%), and 16-20 (9\%) (see figure 1).

There were 46 respondents to the question "Who responds to query letters...," and multiple responses were allowed. Most editors $(n=37)$ chose only one answer to this question, although six editors chose two responses, two editors chose three, and one chose four responses. The "editor-in-chief answers" query letters at 91 percent of the journals, and "associate editors answer" at four percent of the journals. One editor said their journal does not generally respond to query letters, although when they do, it might be the editor-in-chief or the assistant editor. Of the 15 percent $(n=7)$ who selected other, the individuals responding to query letters included persons with the following job titles: special issue editors, co-editors, an assistant editor, and managing editors. 
Of the 46 editors responding to the question "How accurate is the information on your journal's website?" 74 percent chose "very accurate," 24 percent chose "somewhat accurate," and 2 percent chose "not very accurate." Fisher's tests provided no evidence of a relationship between this question and the number of query letters received, the editor's level of appreciation, or whether editors wished to receive more query letters.

A total of 44 respondents provided additional information about their journal website through this open-ended question: "How well do you think your journal website communicates information to authors?" Several indicated that author questions are usually already answered on the website, which matches with responses to this question: "How often do query letter writers ask questions that have answers posted on the journal's website?" $(n=46)$. Most (46\%) said "not very often," 33 percent said "occasionally," and 22 percent said "very often." Fisher's tests provided no evidence of a relationship between this question and the number of query letters received, the editor's level of appreciation, or whether editors wished to receive more query letters.

A few editors indicated issues with the journal website. These editors commented that some of their journal websites did not identify the audience of the journal or scope of the content. A few editors indicated that the information in those sections on their websites was minimal. One editor indicated that the publisher controlled the website content and updates; therefore, it was not as updated as the editor would have liked.

Of the 46 respondents to the question, "Upon reflection, how does the submission of a query letter correspond to the likelihood of the manuscript being assigned for peer review?," most editors (80\%) said query letter submission "did not influence" the likelihood of the manuscript being assigned for peer review, but 15 percent said it "positively influenced"

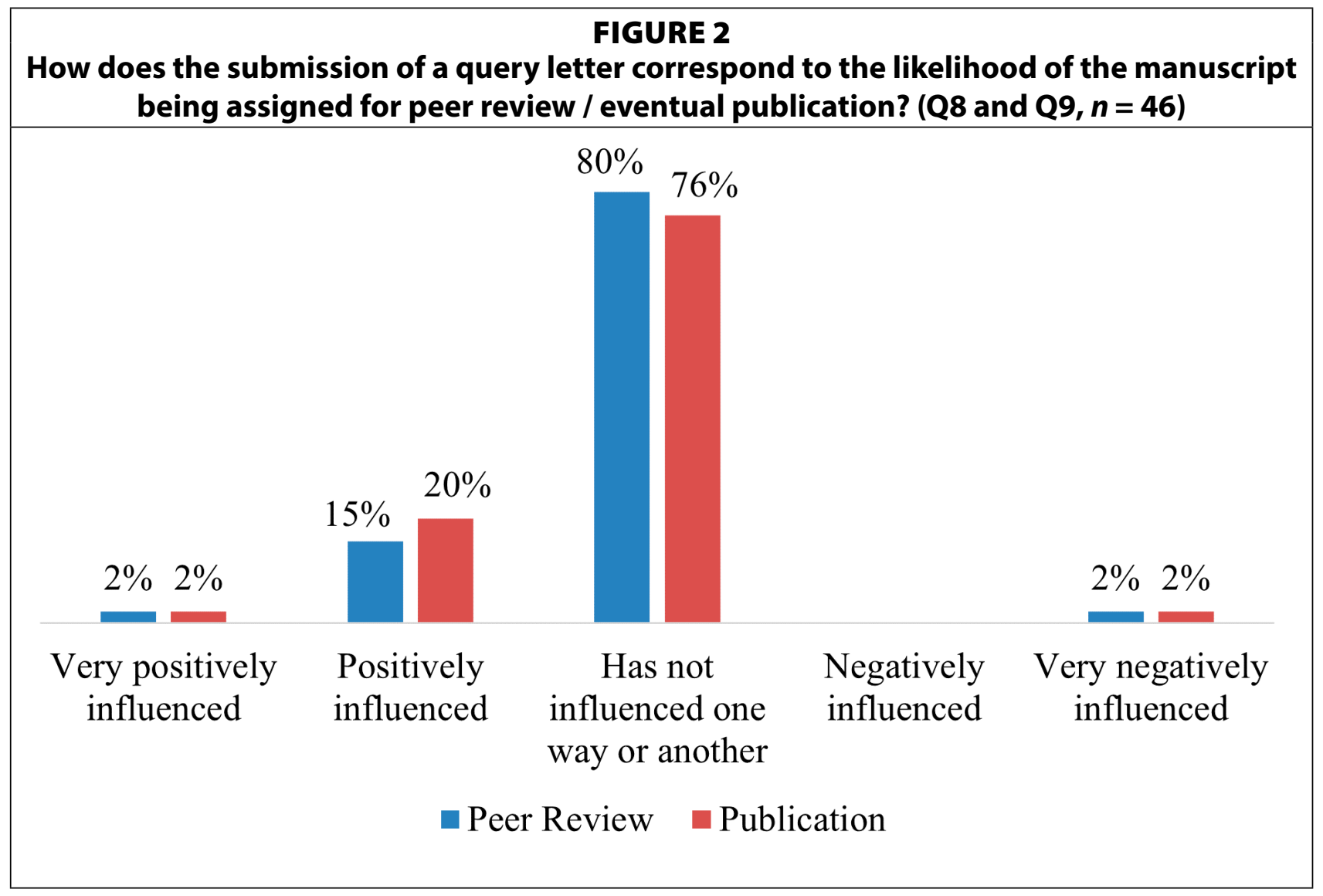


the likelihood of assignment for peer review (see figure 2). One respondent each said that it "very positively" or "very negatively" influenced assignment for peer review. Responses to the next question, "How does the submission of a query letter correspond to the likelihood of eventual publication?" were very similar, although two more respondents said there was a positive influence $(20 \%)$ instead of no influence. Still, only one respondent each said there was a "very positive" or "very negative" influence.

Fisher's tests provided evidence of relationships between wishing for more query letters and whether the manuscript was assigned for peer review $(p=.004)$ and/or eventual publication $(p=.002)$, and between appreciation and eventual publication $(p=.022)$, but not between the level of appreciation and whether the manuscript was assigned for peer review $(p=.056)$. Editors who "wished they received more" query letters were more likely than other editors to say that query letters "positively" or "very positively" correlated with the chance of a manuscript being assigned for peer review and for eventual publication. A similar and statistically significant pattern emerged with appreciation and publication. A similar pattern emerged between appreciation and peer review, but it was not statistically significant. There was one editor who "strongly disagreed" with wishing for more query letters; this editor also felt query letters had a very negative correspondence with peer review and/or publication.

All survey respondents (including the four who receive no query letters) had the option to see the remaining questions. Of the 49 respondents to the question, "I appreciate (or would appreciate) receiving query letters from authors," 61 percent "agreed" or "strongly agreed," while 18 percent "disagreed" or "strongly disagreed," and 20 percent selected "neither agree nor disagree."

Among the 49 respondents to the question, "I wish more authors would write query letters to my journal before submitting their article," there was a little more ambivalence, with only

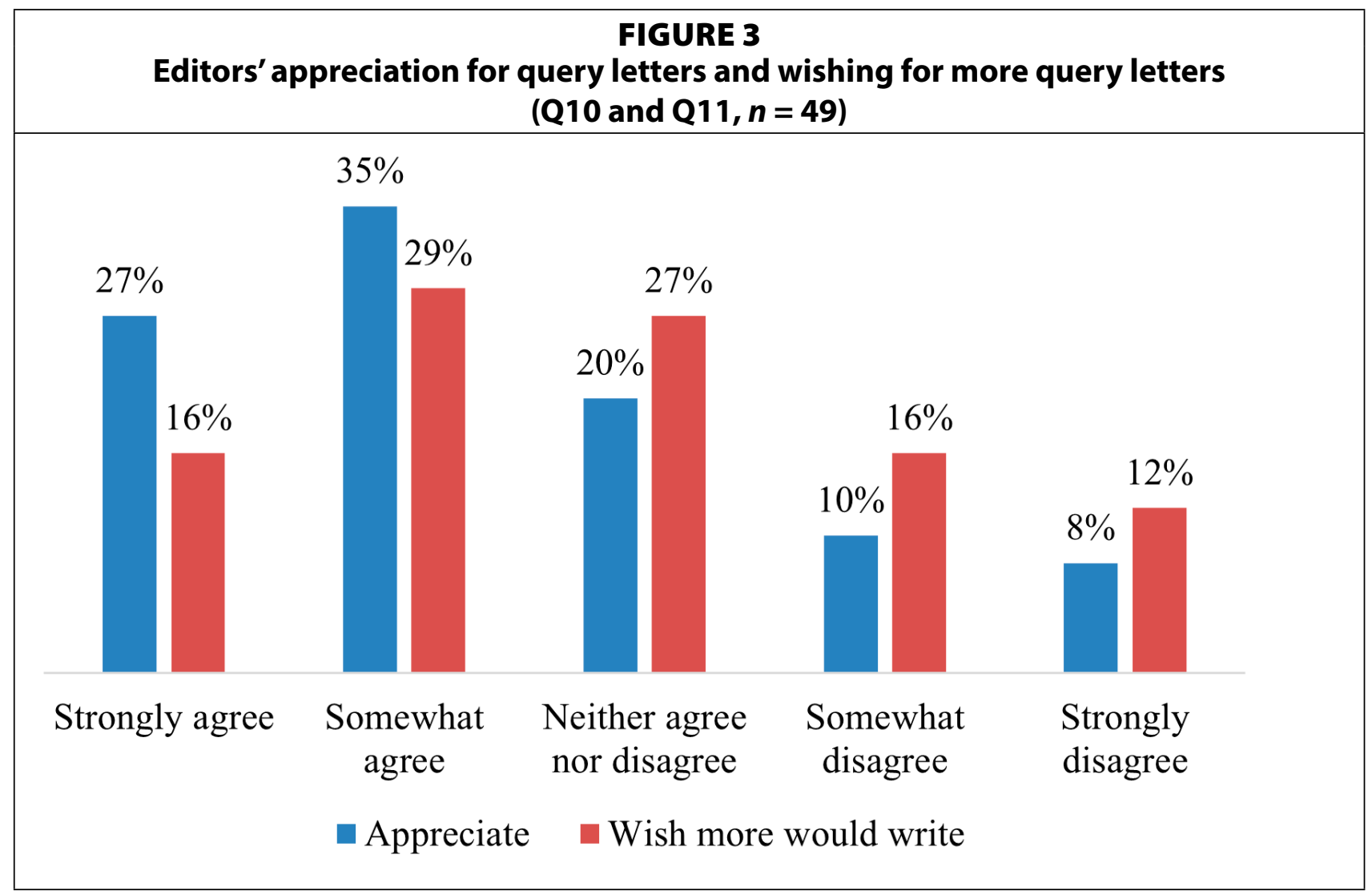


45 percent agreement (and less strong agreement), 29 percent disagreement, and 27 percent selecting "neither agree nor disagree." Thus, editors' appreciation for current efforts seems a bit higher than their interest in receiving more query letters (see figure 3). A Fisher's test provided evidence of a strong relationship between appreciating query letters and wishing for more query letters $(p=.000)$. All of the editors who said they appreciated query letters wished they got more of them, and all of the editors who did not appreciate query letters did not wish for more. Of those who said they neither appreciated nor did not appreciate receiving query letters, none said they wished for more, four said they did not wish for more, and six said "neither."

Fisher's tests showed no significant evidence of a relationship between these two questions and the number of query letters received. However, it is notable that editors who receive more than 20 query letters were less likely than other editors to appreciate them or wish for more - four of the five editors who edit journals receiving more than 20 query letters per year "disagreed" or "strongly disagreed" with the appreciation and wishing-for-more question. Interestingly, the other one of these high-volume editors strongly appreciated query letters and would like even more of them.

The next several questions related to when and how to submit query letters as well as appropriate topics to cover. More of the 49 editors disagreed (49\%) than agreed (35\%) in answer to the question, "It is appropriate for authors to send query letters simultaneously to multiple journal editors," and the most popular response was "strongly disagree" (see figure 4). Sixteen percent answered "neither agree nor disagree." A series of Fisher's tests showed no relationship between responses to this question and to level of appreciation, wishing to receive more/fewer query letters, or the number of query letters received.

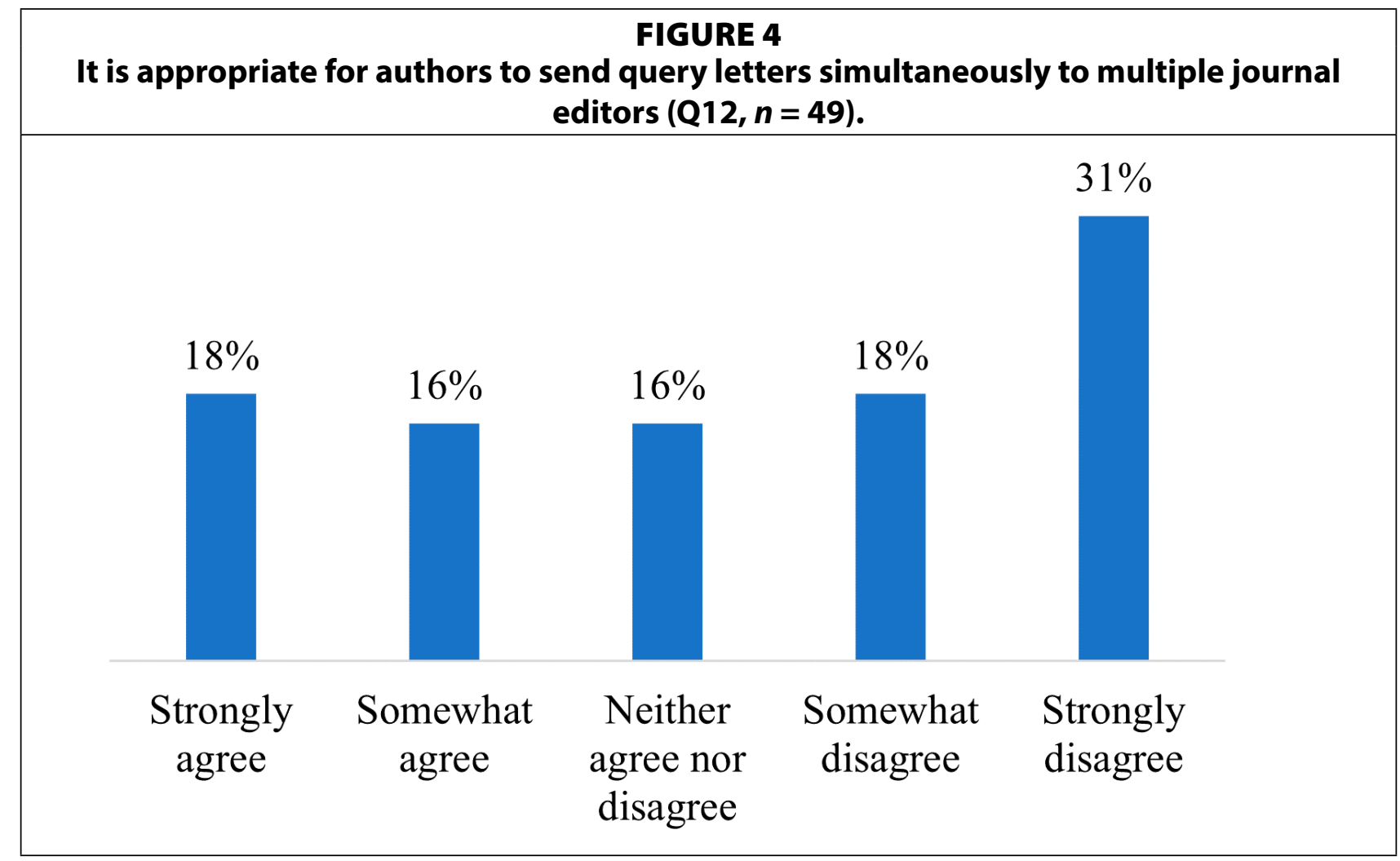




\section{"What questions/topics should authors ask in a typical query letter?" $(Q 13, n=47$ or $n=$ 48, depending on the item)}

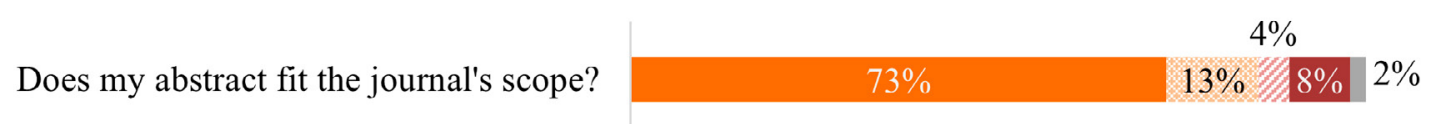

How soon could my article potentially be published?

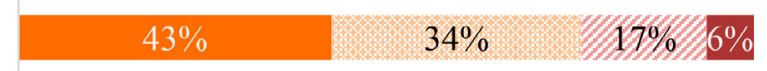

Are the author instructions on the journal website up to date?

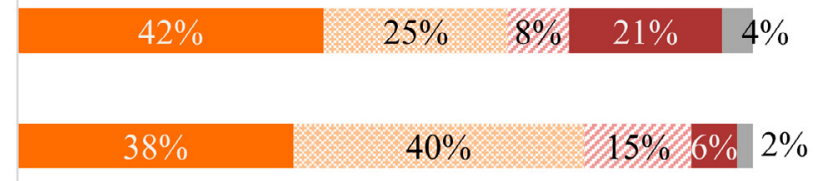

Is it OK if manuscript exceeds your preferred word count limit?

What is your typical turnaround time for peer review?

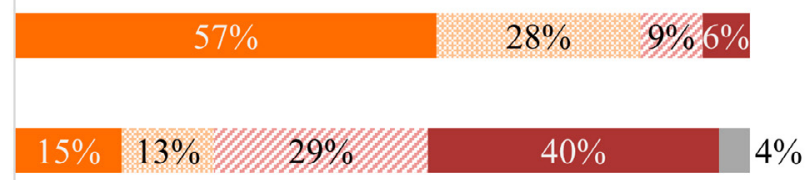

May I submit a manuscript in a different style than what is indicated in the author instructions?

What options are there for making a version of the article publicly available?

$60 \%$ $17 \% \quad 13 \% 9 \% \quad 2 \%$

Entirely appropriate Somewhat appropriate Somewhat inappropriate $\quad$ Not appropriate $\square$ Not Sure

Either 47 or 48 editors responded to each item in the question set, "What questions/topics should authors ask in a typical query letter?" Only one or two editors answered "not sure" to each item. Most editors thought that the questions/topics were at least somewhat appropriate with the exception of "May I submit a manuscript in a different style..." which netted 69 percent negative responses. Full responses for this question are in figure 5.

For only one of these hypothetical questions did a Fisher's test show a relationship with the number of query letters received per year: What is your typical turnaround time for peer review? $(p=.014)$. Editors who receive more than 20 query letters per year were more likely to also say that asking about turnaround time for peer review was "not appropriate" - three of the five editors who receive more than 20 query letters per year said this question was "not appropriate."

Relationships were also found between appreciating and wishing for query letters and the following question: "Does my abstract fit the journal's scope?" (appreciating $p=.001$, wishing $p=.026)$, and between appreciation and the item, "What is your typical turnaround time for peer review?" $(p=.025)$. Editors who strongly "did not appreciate" getting query letters or who "did not wish for more of them" tended to find the scope question more inappropriate. On the peer review question, both groups were split: two of the "strongly do not appreciate" said the peer review question was entirely "appropriate," and two said it was "not appropriate"; similarly, of those who strongly wished not to receive more, three said it was "entirely appropriate" and three said it was "somewhat inappropriate" or "not appropriate."

Fisher's also showed evidence for a positive relationship between answering "neither" for wishing for more query letters and finding the question, "Are the author instructions on the journal website up to date?" not appropriate $(p=.025)$. Six of the 12 "neither" respondents said this question was "not appropriate." 


\begin{tabular}{|c|c|}
\hline \multicolumn{2}{|c|}{$\begin{array}{l}\text { TABLE } 1 \\
\text { Appropriate and inappropriate Topics for Query Letters }\end{array}$} \\
\hline Appropriate Topics for a Query Letter & Inappropriate Topics for a Query Letter \\
\hline $\begin{array}{l}\text { - Appropriateness of the manuscript to the journal's scope } \\
\text { - How often can an author submit to a journal in a specific } \\
\text { time frame } \\
\text { - Acceptable formats for illustration/table files } \\
\text { - Special issue topic proposals } \\
\text { - Copyright questions or institutional repository deposition } \\
\text { options } \\
\text { - Which article type would be most appropriate for their } \\
\text { manuscript } \\
\text { - Possible article topics } \\
\text { - Questions about publication process } \\
\text { - If the journal meets the UK's Research Exercise Framework } \\
\text { deadlines } \\
\text { - Whether a desk review* is possible } \\
\text { - Column opportunities } \\
\text { - Suggestions for material reviews } \\
\text { - "Potential authors should always state that they have } \\
\text { read the information for authors (IFA) and 1) list questions } \\
\text { pertaining to the IFA and 2) list questions with concerns } \\
\text { not covered in the IFA." }\end{array}$ & $\begin{array}{l}\text { - Queries regarding the identities or } \\
\text { credentials of peer reviewers } \\
\text { - Questions about going against the journal's } \\
\text { accepted process, style, guidelines, etc. } \\
\text { - Anything clearly written on the journal's } \\
\text { website or the page with Information for } \\
\text { Authors } \\
\text { - Offering to pay for articles to be published } \\
\text { to speed through the review process } \\
\text { - Authors asking to publish his/her paper } \\
\text { immediately without referee }\end{array}$ \\
\hline . & de this type of review before \\
\hline
\end{tabular}

The survey asked if there were additional topics that are appropriate and those that are not appropriate for journal query letters; the answers are detailed in table 1.

Of the 45 respondents to the question set "When should an author submit their query letter? (check all that apply)," most $(78 \%)$ checked multiple responses. Almost one-third of the editors $(n=14)$ checked all six items, indicating authors should submit queries at any point in the writing process. Only 40 percent of editors chose the first two stages listed, "during ideation or hypothesis development stage-before research has begun" and "while research is underway." More than two-thirds of editors chose each of the last three stages, beginning with "when the manuscript is being written." Full summary of this question set is available in figure 6 .

Fisher's tests showed no evidence of a relationship between answers to these items and the number of query letters received. There was evidence of a relationship between wishing for more queries and one item, "While manuscript is being written" ( $p=.005)$. While, overall, most editors think "While manuscript is being written" is one of the best times to write a query letter, editors who "strongly wished for more query letters" were less likely to select this item than other editors. It is also notable that, of the four editors who "strongly do not appreciate" query letters, none picked any item, except one of them picked "when manuscript is complete or nearly complete."

Finally, survey respondents were given the opportunity to provide any other comments, and 30 editors chose to do so. Their feedback fell into several thematic areas: editors' enjoyment 


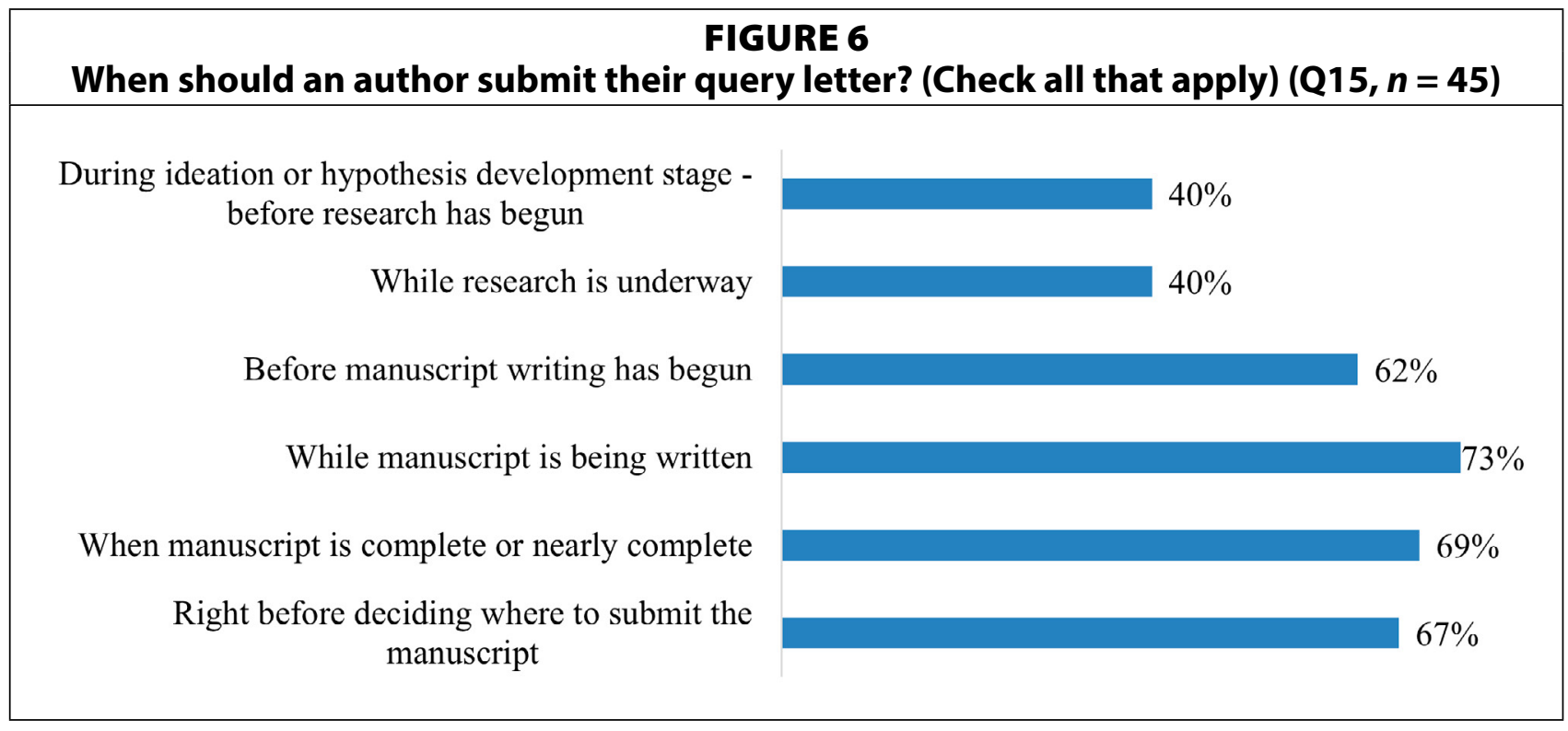

about interacting with authors, recognizing the processes in place for journals and authors around publication, some frustrations with query letters, and other feedback.

Most editors enjoy interactions with authors. One wrote, "as an editor I like to interact with authors. A journal that does not accept or respond to queries should state that in the submission guidelines." Another respondent indicated that query letters really help build up a relationship between author and editor. Several editors mentioned that query letters help to build rapport with authors, shape ideas, and provide feedback or suggestions for improvement. As for tips for authors thinking about writing query letters, LIS journal editors would like authors to read the journal website first and "submit query letters with any questions not satisfactorily answered by the information on the journal website." One editor advised on personalizing the query letter to the potential journal. This editor noted, "the correlation between query letters that give no indication the author has read the available scope or guidelines and ultimate submission of an article is very low: the briefer and more generic the query letter, the less likely the article will be submitted." Another editor noted that "discussion around precise focus can ensure resulting paper is fit for purpose. If there is dialogue at the beginning then that is a good basis for future interaction." Several editors noted that, if articles are out of scope, alternate journals may be suggested.

Several of the comments were related to the publication process. One editor noted many questions related to the type of article being submitted. Another editor found that the earlier people contact the journal, the better chance at publication, especially for new authors who might especially benefit from a query letter earlier in the process as their ideas are coalescing. One editor noted that query letters are "better during earlier stages of research if the questions are about methods, scope or conceptual issues." A few editors indicated that journal selection should be one of the first steps in writing an article since determining where to publish earlier in the process will make it easier to craft the article to "fit" the journal and "sidestep any number of problems at the submission stage." Along these lines, one editor noted that "authors should think realistically about where they might submit a manuscript while they are writing the manuscript. Researching journals should be a part of the process. Understanding scholarly communication and one's discipline or field is a part of being a researcher or author." Several editors noted that query letters provide an easy way to break down scholarly 
publishing barriers and allow authors to feel comfortable sharing ideas or asking questions about the process. Another couple of editors noted query letters may be helpful in boosting confidence of either a first-time author or an author where English is not their first language. However, one editor noted that query letters later in the writing process may "delay the process because the author has to wait for the Editor in Chief to read it, consult the editors if necessary, and respond. A submission would go straight to the Associate Editor who could decide on the scope and whether to send for peer review." Respondents also recognized the reality that authors face and that they try to work positively with authors as much as possible. Editors responding to this survey recognized they are affecting career development and success. One editor noted, "there is stress of promotion and tenure requirements and stress associated with publication itself."

A few editors expressed concerns over query letters. One editor noted that, while query letters "are a natural part of the publishing ecosystem .... natural part of the query letter process is the frustration of hearing from an author about a potential piece, going back and forth with them to offer advice and answer questions, and then never hearing from them again, even if one follows up." Other editors found query letters to be of little value. One editor noted that an abstract rarely provides "enough information to determine the scope of the article." Another editor expressed concerns if query letters became standard practice as they are "a one-person editorial team and would not have time to respond to a query letter from most/all potential submitting authors."

The remainder of the comments fell into general information. One editor noted that after this survey they would have their publisher include more information on the website about query letters in the hopes of reducing the load of articles rejected out of hand due to the fact that they are out of scope for the journal. Some journal editors felt that the number of query letters they received was higher because of their internal journal processes (for example, rolling deadlines, or a voting procedure by the editorial board) rather than due to other factors. Finally, one editor indicated they received some irrelevant article submissions due to the name of the journal and that a query letter could clarify those that are out of scope.

\section{Follow-up Interview Summary}

Each of the four editor interviews followed the same script (see appendix C), and results will be shared in order, with the exception of question 7, on which responses often returned to previous discussion points; these supplement the other summaries when applicable. Overall, each interviewee seemed to have a clear process in their minds about how the whole process works, from any initial communication with the author, through the submission process, peer-review process, and publication. However, it was striking that these processes did not match across editors - for example, one editor commented that he preferred to have a cover letter along with the article submission. All four of these editors struck us as benevolent people who cared deeply about authors, social issues, and the LIS profession. Each editor also noted that they valued their peer reviewers and wanted to save them time by assigning articles for peer review that were likely to be a strong fit for the journal. Their processes related to these shared values conceptually but differed logistically.

Each editor was asked whether they would advise a colleague to submit a query letter and to think about the benefits of a query letter for the author as well as for the journal editor. One interviewee, of a journal that receives 150-200 submissions per year, was espe- 
cially effusive about the benefits of query letters to both editors and authors. As an editor, he appreciated the chance to help "shape the article idea with potential into an acceptable article" and work ahead to perhaps "craft a set of submissions" to fit the journal's purpose. He might say, "well this article would be great but if you talked about THIS it would be much more in scope." Finally, he noted that query letters can lighten the load of peer reviewers, because it improves the quality of what they see, allowing them to do "a more detailed review up front." He sees query letters as a benefit to the profession as it allows for a "lightweight mentoring opportunity." He noted that usually the author is more junior in the profession and editors are typically more senior librarians, so it is a way to shape the profession. Another interviewee was in favor of query letters because it helps the journal editor to know what potential future articles might be coming and possibly would create a thematic issue for emerging topics.

Editors noted that benefits of query letters extend to authors as well. "If you write a query letter before submitting, it helps you focus your article, get some initial feedback from someone who's equivalent to a peer reviewer and help focus it before the reviewer sees it." One editor thought it would save the author time because they could "whittle down the number of journals that will need to see it to get it accepted." Another editor pointed out that authors should use query letters to formalize their ideas and help the ideas evolve before writing the complete article. An editor of a journal that receives 120-125 submissions per year, and who was in favor of query letters, noted that the online submission forms are onerous for authors to fill out and that authors would waste a lot of time if the article is swiftly rejected for being out of scope for the journal, which could easily be established with a query letter. Another editor noted that many of the query letters he receives are from more seasoned scholars who would not want to waste their time on an article that would not fit the journal or be an acceptable topic.

When editors were asked why they thought some survey respondents might "disagree" or "strongly disagree" with wanting more query letters, our editors had only a few ideas. One editor indicated that some editors may not want more query letters because the journals might be centered around preplanned themes or conference-based issues and therefore would prefer not to have articles outside of scope. Another editor noted it could be that, if they received a lot of submissions, their workload may already be unsustainable. Another editor pointed out that many journals use online portal systems for submissions and because that workflow is established, sending a query letter bypasses that process and may make additional work for the editor. The interviewee who did not appreciate query letters and did not want more of them said he preferred for authors to just send their submission, because past query letters rarely resulted in a submitted manuscript.

When asked about why they thought there were such wide-ranging responses to the question about submitting query letters to multiple journals simultaneously, one editor felt very strongly that this was unethical and should be avoided. (This same editor would just prefer to see the submission rather than having the query letter.) Of the three editors who advise colleagues to send letters, two thought sending simultaneous query letters was acceptable. The third indicated that the turnaround time for responses to query letters was often short; so, out of professional courtesy, authors should wait for a response from one journal before querying another. All of the editors interviewed were clear that the submission of the manuscript itself should only be sent to a single journal at a time and that it would be a clear breach of ethics if authors simultaneously submitted a manuscript to different journals. 
The next question focused on the fact that most editors chose multiple responses to the question of when during the research process should a query letter be sent. The editors interviewed saw different benefits to writing query letters at different points in the process. One editor said, if an author submits earlier in the research process, it eases the editor's burden because they can give a quick "yes in scope, no not in scope" or "we've already published too many articles on this topic." Another editor indicated that submitting query letters earlier in the research process allowed for editors to provide more advice on author's methods, scope, or unit of analysis, which typically would result in a better manuscript that the editor would want to review for publication. For query letter submissions later in the research process, one editor indicated that "any time the author considers the article is finished, it's easier for the author to contemplate revisions during the process rather than after submission." One editor noted that it is probably a good idea for authors to think about where the article would be published earlier in the process so that the writing can be tailored to that journal.

When asked about other ways for authors to engage with journal editors, the editors recognized that most authors in LIS journals have not gone through a PhD program and therefore have not had the same level of mentorship in scholarly writing. They noted that query letters may fill some of this void, as they allow authors to get feedback throughout the submission process. Three editors mentioned the editor role of recruiting papers (especially at conferences) or looking through conference listings. One indicated his wish for a new role with the journal for new LIS professionals to solicit articles at conferences. He thought that, if those newer to the field would solicit articles, it would be a good entry point to becoming a reviewer. One editor indicated the importance of a cover letter to a journal article submission explaining why they did their work. This editor thought it was more important for journals that receive a lot of article submissions since the more information the editor has, the easier it is to assign peer reviewers with aligned expertise.

Two additional topics arose that related to editor-author interaction, if not specifically query letters themselves. First, strict adherence to scholarly style requirements at the submission stage varied widely among interviewees; some would send a nonstyled article on to peer reviewers; other editors would return the article to the author if the style did not match the journal requirements. Finally, two of the interviewees edited journals with an international audience or focus. These editors noted that they did not adhere as stringently to issues with language, word choice, or structure for submissions. They both had a two-step editing process where they first work with authors on content and then will help with copyediting and word choice, if necessary.

\section{Discussion}

While query letters to journals are not mentioned as much in the LIS writing literature as they are in nursing and education fields, our survey respondents had many opinions about them. Their responses illuminated ways to further mutual understanding between authors and editors and improve author-editor communication - including, but not limited to, query letters. Survey responses and follow-up interviews unearthed a wealth of editorial lore that may be hidden from authors. LIS editors highly value author interactions and covet high-quality submissions. In fact, they work actively at conferences and from their offices to solicit relevant submissions. Editors do want authors to be judicious in selecting journals and to think about this early in the writing process. They welcome clarifying questions about whether and how 
a given article proposal might fit or whether a topic has already been covered adequately by the journal in the editor's mind. Editors understandably show irritation with questions they feel are obviously answered on journal websites, but they welcome clarification to submission procedures as well as innovative ideas and queries. In sum, while authors may feel as though they want to find any home for their research, approaching editors with respect means learning about their journal before asking questions.

The findings of this study also revealed several areas where editors' perceptions, workflows, and practice may vary widely, even when based on shared professional values and experiences. This may be confusing and even engender anxiety among authors. For example, while all editors have to deal with workload issues, their attitudes and responses toward workload varied. Two interviewed editors of journals with larger number of submissions were among the more excited about query letters, while other editors noted their lack of enthusiasm for queries was due to existing workload. Therefore, authors should be aware that terse replies may be due to the editor being overwhelmed rather than uninterested. Also, while all editors have to balance rigor and empathy, those leaning toward the side of rigor may seem less warm and friendly to authors (and therefore less warm toward query letters) if they focus their communications on quality standards. Editors value professionalism and mutual respect, but their ideas of what specific behaviors qualify (such as simultaneous query letters) may be hidden from authors and from other editors. Furthermore, online submission systems may make it difficult for the editor to send comments to the author outside the formal review process; and, for the author, sending query letters via a web form can feel awkward and often does not allow for formatting. While some of our survey respondents explicitly mentioned author anxiety, other editors may be so familiar with the publishing process that they may have forgotten the feeling.

When it comes to the attitude of editors toward receiving query letters, a majority of editors actively appreciate query letters; some are ambivalent; and some do not appreciate them and do not want more of them. However, writing a query to editors lacking enthusiasm will not necessarily harm one's chances; most of these editors said query letters do not influence peer review or publication. Additionally, the comments from the survey and the interviews revealed that potential irritation with query letters is often centered on inappropriate content in the letters and workload concerns, not with the idea of communication. A good portion of query letters received by editors are of dubious motivation or intent (such as authors offering to pay for being published, or to secure assurance of acceptance). Editors' opinions on the acceptability of simultaneous query letters were split. Some editors thought simultaneous letters can improve efficiency for everyone as authors more quickly find a good fit; but others thought they showed disrespect for the one-to-one nature of the relationship between an editor and an author. Altogether, these results suggest authors can feel confident about writing query letters, but to treat them with the care and respect one takes when applying for a job-namely, doing a little research ahead of time and customizing the query letter for the journal.

From this study, the authors have found that query letters to LIS journals are not only acceptable, they can improve scholarly publishing for both authors and editors. Benefits include opening channels for editors to help authors improve their work and tailor it to specific purposes; reducing the workload for editors and peer reviewers while saving authors' time; helping editors plan ahead for their journals; and mitigating the dehumanizing aspects of journal submission systems. A benefit we see, upon reflection, is for authors to start to get 
to know the editor(s) they may be working with and to tailor their future communications appropriately.

From both the survey and the interviews, most editors did not indicate that query letters have an influence on the likelihood of initiating peer review or publication. However, eight editors (15\%) said there was a positive influence on peer review, and $10(20 \%)$ said there was a positive influence on publication. Supporters of query letters were more likely to see query letters as influential on the peer review and publication process. The interviews suggest this influence relates to the editor and author working together to find a good fit.

Editors agreed that there were acceptable and unacceptable topics for query letters and that authors should examine the journal website before contacting the editor. Editors generally found the presented list of possible questions appropriate, except for the direct question about submitting in a different style. Three questions stood out as especially appropriate, with more than 50 percent of editors answering "Entirely appropriate":

- Does my abstract fit the journal's scope?

- What is your typical turnaround for peer review?

- What options are there for making a version of the article publicly available?

It is notable that the latter two questions involve information often found on the journal's website, and this study confirmed that authors do ask questions that are already answered on the journal website. Moreover, most editors (74\%) perceived their websites as "very accurate" and some comments expressed at least mild irritation when authors ask such questions. However, 24 percent said their websites were only "somewhat accurate," and several offered examples of information missing from their websites. Given that authors encounter a diversity of journal websites, authors have likely experienced cases where the website was incorrect, unclear, or out-of-date. These findings suggest authors need to be diligent about reading the website but may also ask clarifying questions via query letters about particular points of ambiguity.

Editors offered a couple additional questions that would be appropriate to ask that this study's authors had not considered; authors may wish to review them when composing query letters. One question an editor found acceptable to ask in a query letter was whether there was a "limit to the number of submissions from one author in a given time frame." The other question editors found appropriate for query letters were about theme or topic coverage of an article, especially if the topic has been covered already in recent issues. Additional areas that are suitable for query letters would be if an author was planning a series of articles on a specific topic. By sending a query letter, the author can work with the editor to gauge interest, introduce the series, and determine a scope that is more tailored to the journal. While the article(s) would likely have to go through the typical peer-review process, it affords both editors and authors the opportunity to plan out timing for submissions.

The additional questions submitted as "inappropriate" provide more indication of why some editors do not appreciate query letters. However, while editors answering the survey found it inappropriate to ask about submitting in a different style than the journal listed on the website, the interviewed editors reacted very differently. Some editors sympathized with the author's work in potentially reformatting a manuscript and did not feel that the peer-review process is constrained by the wrong style; other editors felt it was more work for the peer reviewers and said they send articles back to the author if they are in the wrong style. 
More editors think authors should submit query letters after research is complete than earlier in the process. However, 40 percent were open to receiving query letters during ideation or research phases, to explore how method and scope could affect appropriateness for the journal. Editors who avidly wish for more query letters seemed most excited to receive them early or late in the process, rather than in the middle, perhaps because they feel they can have the most influence at those points in the research process. Given the findings concerning the benefits and the low risk involved in submitting professionally written query letters, this study suggests authors should write queries whenever they have relevant questions. Although the survey focused on correspondence prior to submission, we note that authors can also write editors after submission - for example, to follow up on submissions that have not received a review within the usual window or to ask for guidance in responding to peer reviewers' comments.

\section{Limitations}

The sampling criteria used in this study limits the generalizability of the findings to Englishlanguage titles in the developed Western world. The impetus behind this focus points to the ongoing global inequity of scholarly publishing-as do some of our respondents' comments, discussed below as an opportunity for future research.

After reviewing survey results, we wished we had asked how many annual submissions each journal received, as this could influence editors' attitudes about query letters. This question was added to the phone interviews. While we would predict that an editor who receives more submissions would prefer fewer query letters, two of the editors from the phone interviews received larger number of submissions annually and were excited to receive query letters.

We chose to select editors of journals with broader scope for interviews and interviewed only four people, meaning the interview findings, while rich, are not generalizable. Given that editors from the survey could opt in to the interviews, the answers given may also have been biased toward being helpful. Yet, many open-ended comments from the survey were also supportive of authors and wanted to have good engagement. In fact, the diversity of perspectives revealed in the interviews suggest that a large number of editors would need to be interviewed before patterns were found, which suggests focus groups of editors could be a good way to proceed in charting the larger research agenda of editorial practices in LIS publishing.

\section{Future Research}

The many inconsistencies regarding editorial tone, submission process, and authors' lack of context for what editors expect from submissions may contribute to unnecessary fear and mystery around the publication process. Editors' positions of power may affect authors in more ways than all might realize. However, while query letters are one way for authors to get to know editors a little better, if everyone wrote query letters, the workload could become unsustainable.

Some journals have editorial philosophy statements that may help authors anticipate and contextualize editor communications. For example, Law Library Journal's website states, "Throughout the editorial process, the editor's purpose is to assist authors in effectively communicating their ideas. The editor welcomes advance queries from authors about possible journal articles." ${ }^{21}$ Other journals employ deliberately developmental submission processes (for example, The code4lib Journal). ${ }^{22}$ Some editors participate in panels at conferences that aim to demystify the publication process, and many visit poster sessions to invite authors to 
submit. Perhaps editorial teams could create videos for journal websites about the journal's ethos, post to social media about their experiences as editors, or provide more information about the submission process on their websites. A group like the now-defunct LIS Editors ${ }^{23}$ could help to harmonize best practices among journal editors and make them more transparent to authors. Overall, research concerning which of these methods are effective for fostering a more equitable LIS scholarly publishing environment would be beneficial.

The centrality of the editor-in-chief in correspondence suggests the roles of other editorial team members are hidden from authors. Yet, respondents' comments highlighted some expanding leadership roles and responsibilities beyond the traditional solo editor-in-chief model. To what extent are these new models of journal leadership taking hold in LIS? How do they affect scholarly publishing? At such journals, what are the perspectives of those in roles other than the editor-in-chief? From this study's authors' experience, editorial board practices vary widely, with some journals having the editorial board solicit articles, contribute columns, or peer-review articles.

Interviewed editors all mentioned concerns related to submissions from authors in the developing world, from empathy for researchers encountering language or marketplace barriers to irritation with predatory journal practices that seem to affect the developing world disproportionately. There are journals like the IFLA Journal and International Information $\mathcal{E}$ Library Review addressing these inherent inequities by broadening coverage and including political, social, and economic influences on access to information (http://uk.sagepub.com/ en-gb/eur/journal/ifla-journal\#ManuscriptPreparation), but examining this area as part of a future research agenda is important.

\section{Conclusion}

Authors' work and ideas have inherent value, and their engaged participation strengthens the scholarly communication process. Query letters may be one good way for authors to overcome anxiety, take initiative, and participate more actively with journal editors. Writing query letters - with care and mutual respect-can increase the likelihood of finding an appropriate home for one's scholarship, and of fitting one's work into the larger scholarly landscape. Creative ideas from authors may spur innovation in LIS journal practices. Guidance from editors can help improve those ideas and methods earlier in the process, resulting in more meaningful scholarship. Practically, query letters can save time for everyone involved and ultimately increase the likelihood of publication. As part of this dynamic, authors need to be open to editors' perspective when they provide feedback about ideas and topics.

As editors seek to encourage valuable contributions, they and their teams should continue to investigate author-editor communication needs and explore possibilities that enhance scholarly communication for all -including the possibilities opened up when authors send thoughtful query letters. Editors should remember the power differential and the lack of transparency in their processes and help authors overcome related barriers. Editors, as a professional community, could reflect on their communications with authors and how their roles impact scholarly communication. As one of the Association of College and Research Library's strategic goals is to "accelerate the transition to more open and equitable systems of scholarship, ${ }^{24 "}$ " LIS editors may have more of a responsibility to do this than editors from other disciplines. Together, authors and editors can improve the state of LIS literature through fostering openness and engagement-prior to the scholarly article submission and review process. 


\section{APPENDIX A. Survey Tool}

Q1 Thank you for participating in this study of query letters to LIS Journals!

This research is being conducted by Meris Longmeier of Ohio State University and Jody Fagan of James Madison University. Unless you identify yourself or your journal, your responses will remain anonymous, and any identifiable information will be kept confidential to the researchers.

After you submit the survey, you will be given the option to enter your email address if you would be interested in participating in a follow-up interview: email addresses entered have no connection to the survey below.

For the purposes of this survey, a "query letter" is defined as an unsolicited proposal or inquiry concerning the suitability of the author's manuscript for publication by that journal.

Q2 What journal(s) do you currently edit? (OPTIONAL) (Free text)

If you currently edit multiple journals, please select just one to keep in mind as you complete this survey. If you would like to submit multiple surveys (one for each journal you edit), you are welcome to do so.

Q3 How many query letters does your journal receive in an average year?

- None (if this was selected, respondents skipped to Q10)

- $1-5$

- $6-10$

- $11-15$

- $16-20$

- More than 20

Q4 Who responds to query letters for your journal (check all that apply)?

- The editor-in-chief

- Associate editors

- Editorial board members

- Other

- My journal does not generally respond to query letters

Q5 How accurate is the information on your journal's website?

- Very accurate

- Somewhat accurate

- Not very accurate

Q6 How well do you think your journal website communicates information to authors? (Free text)

Q7 How often do query letter writers ask questions that have answers posted on the journal's website?

- Very often 
- Occasionally

- Not very often

Q8 Upon reflection, how does the submission of a query letter correspond to the likelihood of the manuscript being assigned for peer review?

- Very positively influenced

- Positively influenced

- Has not influenced one way or another

- Negatively influenced

- Very negatively influenced

Q9 How does the submission of a query letter correspond to the likelihood of eventual publication?

- Very positively influenced

- Positively influenced

- Has not influenced one way or another

- Negatively influenced

- Very negatively influenced

Q10 I appreciate (or would appreciate) receiving query letters from authors.

- Strongly agree

- Somewhat agree

- Neither agree nor disagree

- Somewhat disagree

- Strongly disagree

Q11 I wish more authors would write query letters to my journal before submitting their article.

- Strongly agree

- Somewhat agree

- Neither agree nor disagree

- Somewhat disagree

- Strongly disagree

Q12 It is appropriate for authors to send query letters simultaneously to multiple journal editors.

- Strongly agree

- Somewhat agree

- Neither agree nor disagree

- Somewhat disagree

- Strongly disagree

Q13 What questions/topics should authors ask in a typical query letter? Each of these questions had a Likert scale response of: Entirely appropriate, somewhat appropriate, somewhat inappropriate, not appropriate, not sure

- Does my abstract fit the journal's scope? 
- How soon could my article potentially be published?

- Are the author instructions on the journal website up to date?

- Is it OK if manuscript exceeds your preferred word count limit?

- What is your typical turnaround time for peer review?

- May I submit a manuscript in a different style than what is indicated in the author instructions?

- What options are there for making a version of the article publicly available?

Q14 Please share any further opinions about what questions/topics might be appropriate or inappropriate for authors to cover in a query letter? (Free text)

You're on the last page! Thanks for staying with us :)

Q15 When should an author submit their query letter? (Check all that apply)

- During ideation or hypothesis development stage-before research has begun

- While research is underway

- Before manuscript writing has begun

- While manuscript is being written

- When manuscript is complete or nearly complete

- Right before deciding where to submit the manuscript

Q16 What other comments or perspectives do you have about author query letters? (Free text) 


\section{APPENDIX B. Phone Interview Questions}

1. Did you feel our survey captured the main points of interest related to query letters?

What might have been missing? What didn't we ask that you think we should have?

2. How many article submissions does your journal receive per year?

3. Thinking not so much with your editor hat, but with your "librarian colleague" hat on, should authors write query letters? What are the benefits to authors? What are the benefits to journals?

4. Would you advise your colleagues to write query letters before submitting?

5. Here are the responses to the statement "I appreciate (or would appreciate) receiving query letters from authors":

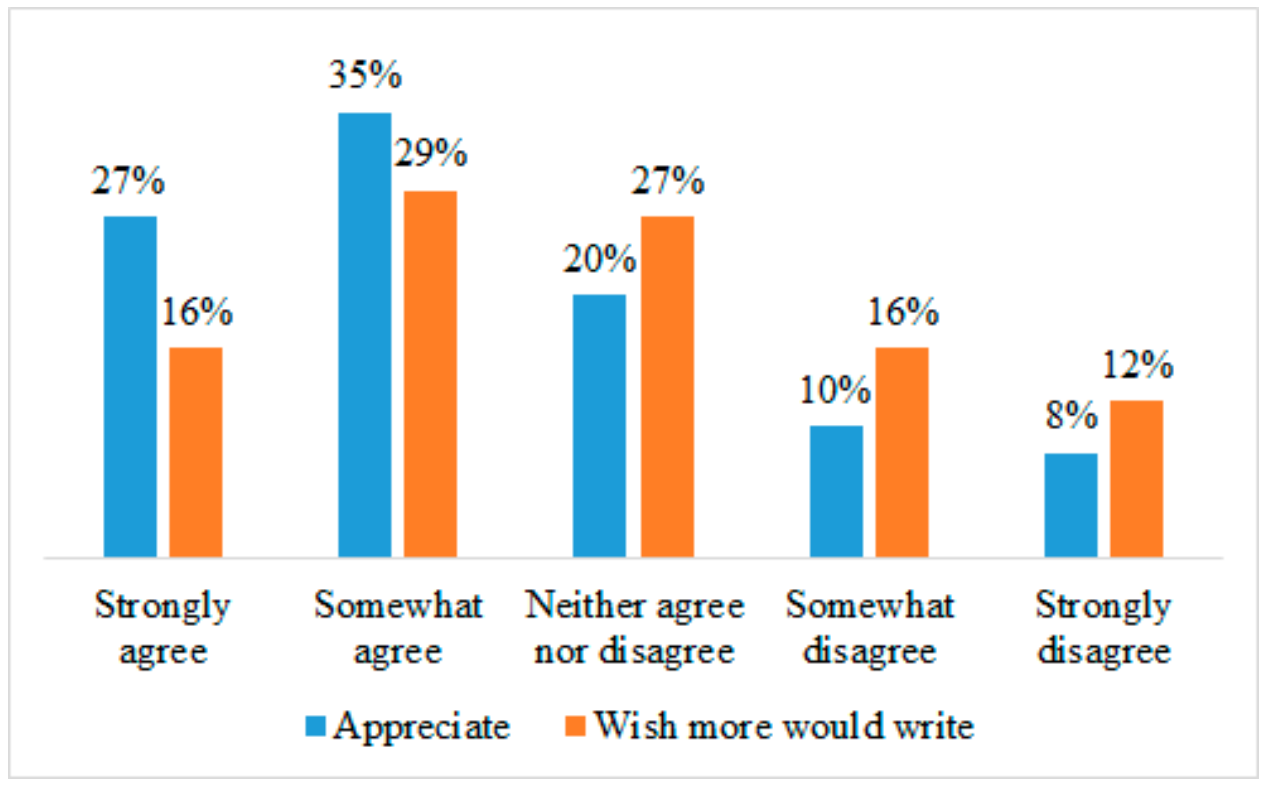

6. Why do you think some editors said "disagree/strongly disagree" to wanting more query letters? / appreciating more query letters?

7. Here are the responses to the question, "It is appropriate for authors to send query letters simultaneously to multiple journal editors":

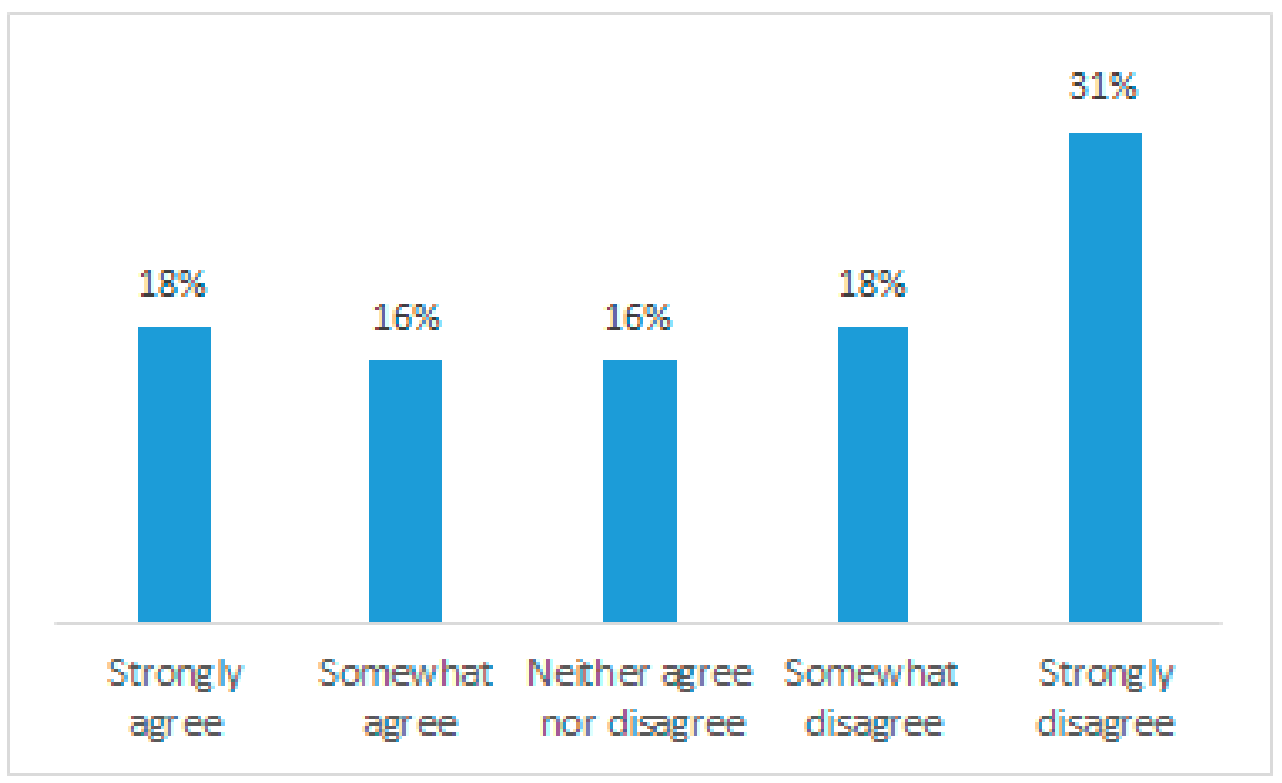


Talk to us about simultaneous query letters - did you think this was okay or not, and why?

8. On the item "When should an author submit their query letter," almost one-third of the editors (14) checked all six items, indicating authors should submit queries at any point in the writing process - most editors checked multiple responses. Why do you think this is?

9. How much of writing query letters is that authors may not understand the journal submission process or peer review process, versus having specific questions about the journal?

10. Query letters are one way for authors to engage with the scholarly process. Would you share with us other ideas related to author engagement?

11. Any other comments or thoughts about our research? 


\section{APPENDIX C. Journals Participating in This Study}

While the survey was anonymous, 39 of 53 editors chose to include their journal's name; these are listed below.

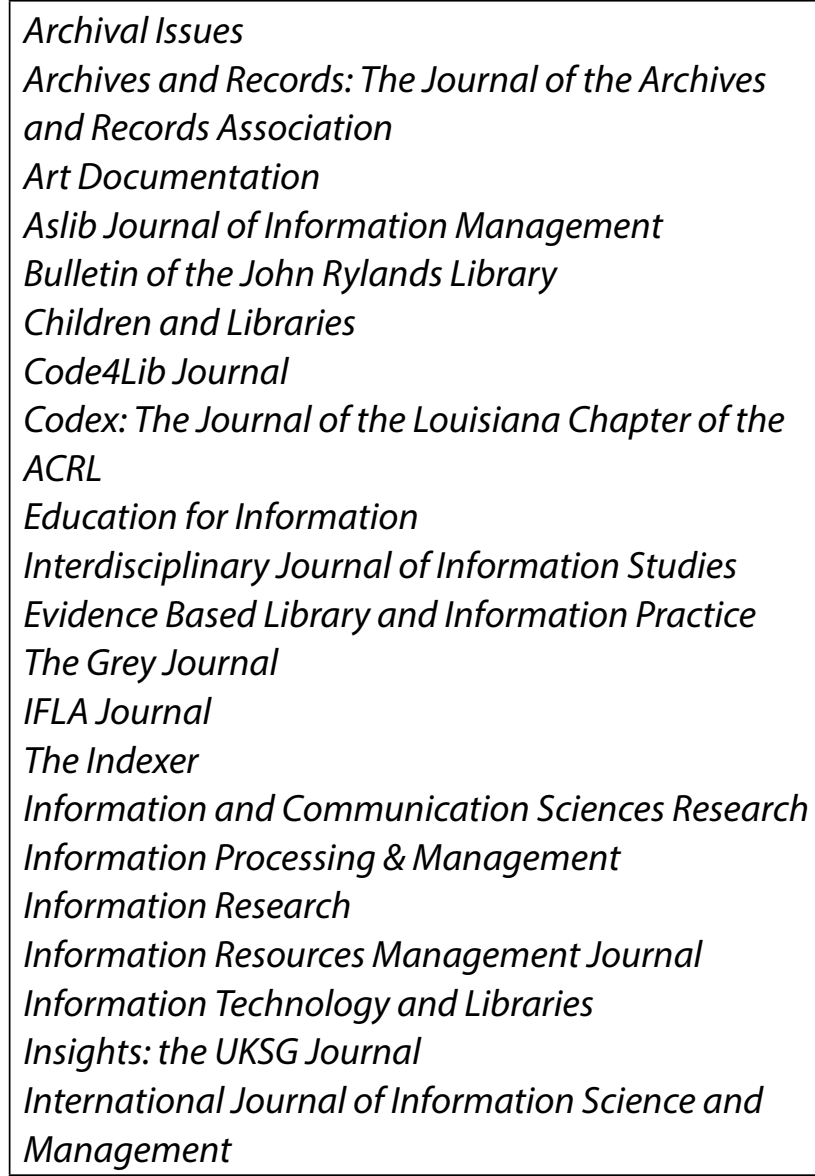

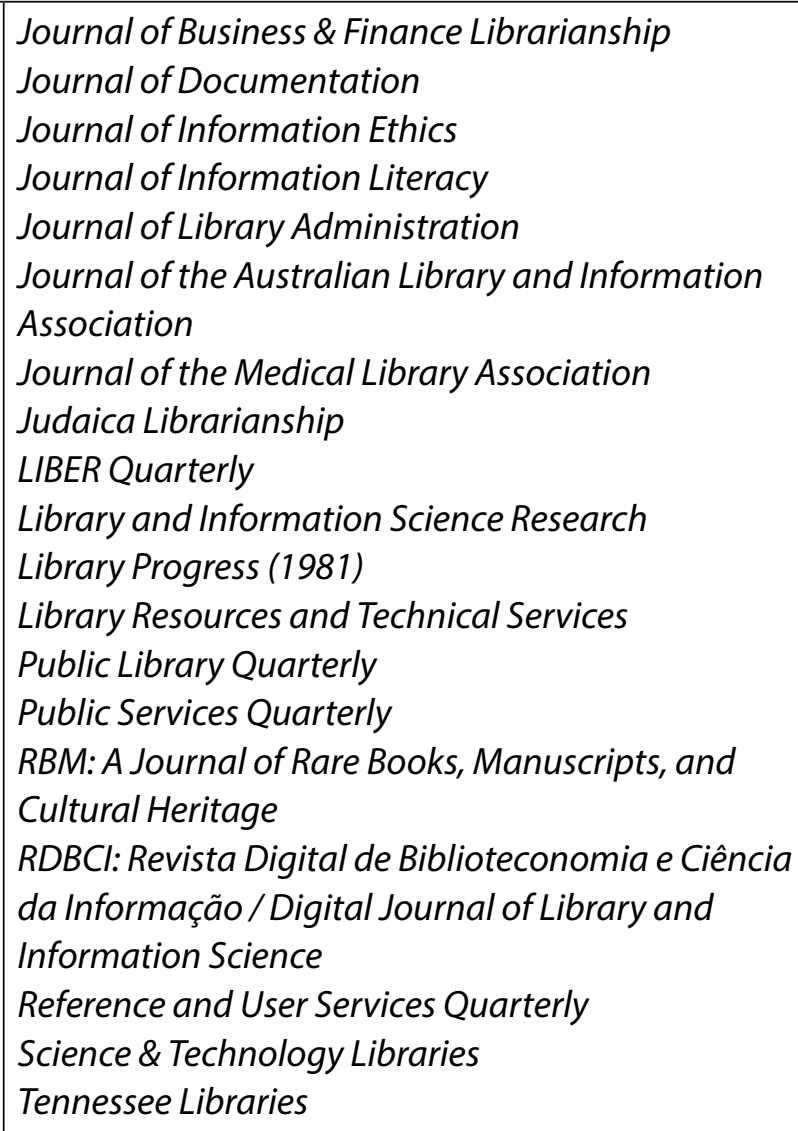

\section{Notes}

1. Meris Mandernach Longmeier and Jody Condit Fagan, "Finding a Good Fit Faster: Tips for Writing Query Letters to LIS Journals," College \& Research Libraries News 82, no. 6 (2021): 269-271, 274

2. Cynthia Tysick and Nancy Babb, "Writing Support for Junior Faculty Librarians: A Case Study," Journal of Academic Librarianship 32, no. 1 (2006): 94-100.

3. Michael Marinello and Ronald W. Hicks, "Reemphasizing the Value of Query Letters in the Digital Age," Journal of the American Association of Nurse Practitioners 31, no. 3 (2019): 147-48; Denise F. Polit and Sally Northam, "Publication Opportunities in Non-nursing Journals," Nurse Educator 35, no. 6 (2010): 237-42; Patricia Gonce Morton, "Tips for Selecting a Topic for a Journal Article," Nurse Author \& Editor 29 (2019): 1; Kenneth T. Henson, "Writing for Education Journals," Phi Delta Kappan 69, no. 10 (1988): 752-54; Kenneth T. Henson, "Writing for Professional Journals," Phi Delta Kappan 80, no. 10 (1999): 780-83; Richard Gargiulo, Mary Renck Jalongo, and Jacqueline Motari, "Writing for Publication in Early Childhood Education: Survey Data from Editors and Advice to Authors," Early Childhood Education Journal 29, no. 1 (2001):17-23; Kerry Dhakal and Joni Tornwall, "The Scholarship Circle: An Introduction to Writing for Publication for Nursing Faculty," Journal of the Medical Library Association 108, no. 1 (2020): 98-105.

4. Sally Northam et al., "Journal Editor Survey: Information to Help Authors Publish," Nurse Educator 35, no. 1 (2010): 29-36.

5. Marinello and Hicks, "Reemphasizing the Value of Query Letters in the Digital Age."

6. Patricia Gonce Morton, "College of Nursing, University of Utah.” Writing for Professional Journals, available online at https://nursing.utah.edu/journalwriting/ [accessed 14 October 2020]. 
7. Henson, "Writing for Education Journals."

8. Hedy Fairbairn et al., "A Profile of Education Journals," in AARE 2008 International Educational Research Conference (2009).

9. Gargiulo, Jalongo, and Motari, "Writing for Publication in Early Childhood Education."

10. Michelle L. Amodei et al., "Survey of Publication Outlets in Early Childhood Education: Descriptive Data, Review Processes, and Advice to Authors," Early Childhood Education Journal 41, no. 2 (2013): 115-23.

11. R. D. Johnson, "The Journal Article," in Librarian/Author: A Practical Guide on How to Get Published, ed. BettyCarol Sellen (New York, NY: Neal-Schuman Publishers, 1985), 21-35; Michael Lorenzen, "Getting Published: An Overview for Off-Campus Librarians," Journal of Library Administration 49, no. 1/2 (2009): 23-33; Rachel Singer Gordon, The Librarian's Guide to Writing for Publication (Lanham, MD: Scarecrow Press, 2004).

12. Lorenzen, "Getting Published."

13. Christian Schloegl and Wolfgang Petschnig, "Library and Information Science Journals: An Editor Survey," Library Collections, Acquisition and Technical Services 29, no. 1 (2005): 4-32. Elizabeth Ehrhardt Mustaine and Richard Tewksbury, "A Survey of Social Science Journal Editors for Behind-the-Scenes Data on the Publication Process," Journal of Scholarly Publishing 47, no. 3 (2016): 232-49.

14. Camielle Crampsie, Tina Neville, and Deborah Henry, "Academic Librarian Publishing Productivity: An Analysis of Skills and Behaviors Leading to Success," College $\mathcal{E}$ Research Libraries 81, no. 2 (2020): 248-71; Helen Fallon, "Librarian as Communicator: Case Studies and International Perspectives," New Review of Academic Librarianship 22, no. 2/3 (2016): 107-11; Helen Fallon, “Using a Blended Group Learning Approach to Increase Librarians' Motivation and Skills to Publish," New Review of Academic Librarianship 18, no. 1 (2012): 7-25; Helen Fallon, "A Writing Support Programme for Irish Academic Librarians," Library Review 58, no. 6 (2009): 414-22; Helen Fallon et al., "Practice and Projects as a Basis for Academic Publishing: Case Study from Maynooth University Library," Insights: The UKSG Journal 32 (2019).

15. Corey Seeman, “Resources for ALA Program: Why can't Johnnie and Jane Get Published: Part 2, Research Methodologies," A Library Writer's Blog, available online at http://librarywriting.blogspot.com/2005/06/resourcesfor-ala-program-why-cant.html [accessed 12 October 2020]; Association for Library Collections and Technical Services, "Research Survey Methods: An ALCTS Annual Conference Program, Why Can't Johnnie and Jane Get Published? Part 3, Research Survey Methods," Research Survey Methods, available online at www.ala.org/ alcts/events/ac/2007/getpublished [accessed 12 October 2020]; Beth Black, "Notes from a Panel Discussion: ALA 2007-Editors Panel Discussion from Why Can't Johnnie and Jane Get Published," available online at https:// library.osu.edu/document-registry/docs/473/stream [accessed 12 October 2020].

16. https://librariangoddess.wordpress.com/2017/07/24/journal-articles-the-thing-explainer-version/ [accessed 12 October 2020].

17. Schloegl and Petschnig, "Library and Information Science Journals: An Editor Survey."

$18 \mathrm{http} / / /$ academicwritinglibrarian.blogspot.com/p/top-tips-from-journal-editors.html [accessed 12 October 2020].

19. Razia Azen and Cindy M. Walker, Categorical Data Analysis for the Behavioral and Social Sciences (New York, NY: Routledge, 2011), 61-68. Because the Likert-type items do not combine to form a trait or attitude, responses do not follow a normal distribution on most items, and the sample size was not sufficient, Fisher's test was used instead of chi-square tests.

20. Azen and Walker, Categorical Data Analysis for the Behavioral and Social Sciences, 60.

21. https://www.aallnet.org/resources-publications/publications/law-library-journal/llj-policy/ [accessed 11 October 2020].

22. https://journal.code4lib.org/process-and-structure [accessed 7 October 2020].

23. www.lis-editors.org/about/index.html [accessed 7 October 2020].

24. https://www.ala.org/acrl/aboutacrl/history/history [accessed 6 July 2021]. 